BRIEF

\title{
Availability, Price, and Quality of Fruits and Vegetables in 12 Rural Montana Counties, 2014
}

\author{
Carmen Byker Shanks, PhD; Selena Ahmed, PhD; Teresa Smith, PhD; \\ Bailey Houghtaling, BS; Mica Jenkins, BS; Miranda Margetts, MS, LLM; \\ Daniel Schultz, BS; Lacy Stephens, BS
}

Suggested citation for this article: Byker Shanks C, Ahmed S, Smith T, Houghtaling B, Jenkins M, Margetts M, et al. Availability, Price, and Quality of Fruits and Vegetables in 12 Rural Montana Counties, 2014. Prev Chronic Dis 2015; 12:150158. DOI: http://dx.doi.org/10.5888/pcd12.150158.

\section{PEER REVIEWED}

\section{Abstract}

We assessed the consumer food environment in rural areas by using the Nutrition Environment Measures Survey for Stores (NEMS-S) to measure the availability, price, and quality of fruits and vegetables. We randomly selected 20 grocery stores (17 rural, 3 urban) in 12 Montana counties using the 2013 US Department of Agriculture's rural-urban continuum codes. We found significant differences in NEMS-S scores for quality of fruits and vegetables; of 6 possible points, the mean quality score was 4.5; of rural stores, the least rural stores had the highest mean quality scores (6.0). Intervention strategies should aim to increase fruit and vegetable quality in rural areas.

\section{Objective}

Rural populations are disproportionately affected by obesity and its associated chronic diseases (1). Access to healthy food is key in promoting intake of nutrient-dense foods that prevent nutrition-related chronic disease and obesity (2). Food environments with accessible and affordable healthful foods support healthful individual food choices and consumption (3). Research on food and store quality in the rural food environment is limited (4). A recent systematic review of the consumer food store environment found 3 times as many audits of urban environments $(n=39)$ as rural environments $(n=13)$; it also found the Nutrition Environment Measures Survey for Stores (NEMS-S) to be most frequently used to assess food availability (5). Of the 13 audits of the rural consumer food environment, only 8 used the NEMS-S. The objective of this study was to assess the consumer food environment in rural areas in Montana by using the NEMS-S to measure the availability, price, and quality of fruits and vegetables (5).

\section{Methods}

This observational study of grocery stores in rural Montana towns was conducted from January to November 2014. NEMS-S was used to assess the availability, price, and quality of fruits and vegetables. Development and testing of the measurement tool is described elsewhere (6). The study was exempt from review.

Study sites were randomly selected on the basis of the 2013 US Department of Agriculture's rural-urban continuum codes (RUCCs) (7). RUCCs range from 1 through 10: ranges 1 through 3 are classified as metro (urban; counties in metro areas; population $\geq 250,000$ ), and 4 through 10 as nonmetro (rural; counties not in metro areas; population $<250,000$ ). No counties in the United States are classified as 10 . We selected sites with a RUCC classification of 6 or higher (population $<20,000$ ).

Rural counties were randomly selected from a master list of Montana RUCCs by using a random number generator. Random selection of sites continued until at least 3 counties were identified for each RUCC classification 6 through 9. One urban control county was randomly selected.

The largest town by population size was systematically selected in each county. When a county was selected more than once, the next largest town by population size was selected. In each town, the largest grocer was selected (only 1 rural town selected had more than 1 grocer). Given the density of large grocers of the same size in the urban control county (Missoula County), we selected 3 urban stores. 
The sample consisted of 20 stores in 17 towns in 12 counties. Six grocery stores were selected in RUCC 6, three grocery stores in RUCC 7, 4 grocery stores in RUCC 8, 4 grocery stores in RUCC 9. The rural counties were Choteau, Gallatin, Glacier, Jefferson, Lake, Madison, Meagher, Mineral, Pondera, Sanders, Teton, and Wheatland.

We calculated averages for total NEMS-S score (54 possible points), availability score (30 possible points), price score (18 possible points), and quality score (6 possible points) for fruits and vegetables. SAS version 9.2 (SAS Institute Inc) was used for statistical analysis. We used analyses of covariance to examine differences in county data $(P<.05)$ and the Bonferroni correction to detect significant differences in pairwise comparisons $(P<.01)$. Overall $P$ values for differences in NEMS-S scores by 2013 RUCC (by county location of store) were obtained by using the Kruskal-Wallis test (7). Significance was set at a 2 -sided $\alpha$ level of .05. A sensitivity analysis was conducted by using the Fisher exact test to determine significant differences in scores by county rurality.

\section{Results}

We found significant differences in sociodemographic characteristics by county (Table 1). One in 5 residents $(19 \%)$ was aged 65 years or older, $84 \%$ were non-Hispanic white, $90 \%$ had at least a high school degree, and $20 \%$ were living below the poverty level. The average household consisted of 2.4 members. Half of the stores $(50 \%)$ were located on an Indian reservation, and most stores (88\%) accepted the Supplemental Nutrition Assistance Program.

For fruits and vegetable in all 20 stores, the (mean) NEMS-S total score was 23.8; availability score, 17.1; price score, 2.9; and quality score, 4.5. NEMS-S total scores, availability scores, and price scores did not differ by county rurality, but quality scores did (Table 2). Of stores in rural counties, stores in the least rural area (RUCC 6) had the highest quality scores (mean, 6.0).

\section{Discussion}

Research exploring rural food access has used limited parameters, such as number of food stores within a certain radius (4); few studies have used NEMS-S (5). This study used NEMS-S and demonstrated that availability and price of fruits and vegetables did not differ by rurality. However, quality was significantly lower in more rural locations.
Rural residents are less likely than their urban counterparts to consume 5 servings of fruits and vegetables per day (8), are at higher risk for diabetes and heart disease, and are more likely to be obese (9-11). Montana adults consume a daily median of 1.0 fruit serving and 1.6 vegetable servings (12); rural adults are less likely than nonrural adults in Montana to consume 5 or more daily servings of fruits and vegetables (8). Fruit and vegetable consumption is associated with lower rates of chronic disease (13).

Broad study findings provide some insight on factors that influence the quality of produce (14); food stores are less available in rural than in urban areas (15), and physical infrastructure is a major barrier to food access in rural areas (16). Future research should focus on finding solutions for improving the quality of fruits and vegetables and its impact on purchases and consumption. We hypothesize that limited infrastructure for food distribution (eg, roads, storage, frequency of delivery) in rural areas poses obstacles to maintaining high-quality produce. Additionally, poorquality produce may drive rural consumers from the produce aisle to processed foods.

This study was limited to rural locations in Montana; application of results may be inappropriate in other locations. Because of the extensive driving time between study sites and weather and road conditions in Montana, data collection took place during 11 months; this long data collection period may have affected NEMS-S scores. Also, rural residents might purchase fruits and vegetables from places other than the largest grocer in their town.

Findings indicate the need for research and intervention strategies that are tailored to rural areas, increase produce quality, improve dietary and health outcomes, and decrease health disparities.

\section{Acknowledgments}

This research was supported by Montana National Institutes of Health INBRE (IDeA Network of Biomedical Research Excellence) (S.A., C.B.S, grant no. 415-1081).

\section{Author Information}

Corresponding Author: Carmen Byker Shanks, PhD, Food and Health Lab, Department of Health and Human Development, Montana State University, 121 PE Complex, Bozeman, MT 59715. Telephone: 406-994-1952. Email: cbykershanks@montana.edu.

\footnotetext{
The opinions expressed by authors contributing to this journal do not necessarily reflect the opinions of the U.S. Department of Health and Human Services, the Public Health Service, the Centers for Disease Control and Prevention, or the authors' affiliated institutions.
} 
Author Affiliations: Selena Ahmed, Bailey Houghtaling, Mica Jenkins, Miranda Margetts, Daniel Schultz, Lacy Stephens, Montana State University, Bozeman, Montana; Teresa Smith, Gretchen Swanson Center for Nutrition, Omaha, Nebraska.

\section{References}

1. Larson NI, Story MT, Nelson MC. Neighborhood environments: disparities in access to healthy foods in the U.S. Am J Prev Med 2009;36(1):74-81.

2. White M. Food access and obesity. Obes Rev 2007;8(Suppl 1):99-107.

3. Story M, Kaphingst KM, Robinson-O'Brien R, Glanz K. Creating healthy food and eating environments: policy and environmental approaches. Annu Rev Public Health 2008; 29(1):253-72.

4. Beaulac J, Kristjansson E, Cummins S. A systematic review of food deserts, 1966-2007. Prev Chronic Dis 2009;6(3):A105.

5. Gustafson A, Hankins S, Jilcott S. Measures of the consumer food store environment: a systematic review of the evidence 2000-2011. J Community Health 2012;37(4):897-911.

6. Glanz K, Sallis JF, Saelens BE, Frank LD. Nutrition Environment Measures Survey in stores (NEMS-S): development and evaluation. Am J Prev Med 2007; 32(4):282-9.

7. Rural-urban continuum codes. Washington (DC): US Department of Agriculture, Economic Research Service; 2013. http://www.ers.usda.gov/data-products/rural-urban-continuumcodes.aspx. Accessed March 3, 2015.

8. Lutfiyya MN, Chang LF, Lipsky MS. A cross-sectional study of US rural adults' consumption of fruits and vegetables: do they consume at least five servings daily? BMC Public Health 2012;12(1):280.

9. Lutfiyya MN, Lipsky MS, Wisdom-Behounek J, InpanbutrMartinkus M. Is rural residency a risk factor for overweight and obesity for U.S. children? Obesity (Silver Spring) 2007; 15(9):2348-56.

10. Befort CA, Nazir N, Perri MG. Prevalence of obesity among adults from rural and urban areas of the United States: findings from NHANES (2005-2008). J Rural Health 2012; 28(4):392-7.

11. O'Connor A, Wellenius G. Rural-urban disparities in the prevalence of diabetes and coronary heart disease. Public Health 2012;126(10):813-20.
12. Centers for Disease Control and Prevention. State indicator report on fruits and vegetables, 2013. Atlanta (GA): Centers for Disease Control and Prevention, US Department of Health and Human Services; 2013. http://www.cdc.gov/nutrition/ downloads/State-Indicator-Report-Fruits-Vegetables-2013.pdf. Accessed April 27, 2015.

13. Wang X, Ouyang Y, Liu J, Zhu M, Zhao G, Bao W, et al. Fruit and vegetable consumption and mortality from all causes, cardiovascular disease, and cancer: systematic review and dose-response meta-analysis of prospective cohort studies. BMJ 2014;349:g4490. Erratum in BMJ 2014;349:5472.

14. Walker RE, Keane CR, Burke JG. Disparities and access to healthy food in the United States: a review of food deserts literature. Health Place 2010;16(5):876-84.

15. Powell LM, Slater S, Mirtcheva D, Bao Y, Chaloupka FJ. Food store availability and neighborhood characteristics in the United States. Prev Med 2007;44(3):189-95.

16. Smith C, Morton LW. Rural food deserts: low-income perspectives on food access in Minnesota and Iowa. J Nutr Educ Behav 2009;41(3):176-87.

\footnotetext{
The opinions expressed by authors contributing to this journal do not necessarily reflect the opinions of the U.S. Department of Health and Human Services, the Public Health Service, the Centers for Disease Control and Prevention, or the authors' affiliated institutions.
} 


\section{Tables}

Table 1. Characteristics of County Rural Subgroups in Montana $(n=20)$, Study on Availability, Price, and Quality of Fruits and Vegetables, 2014

\begin{tabular}{|c|c|c|c|c|c|c|c|}
\hline Characteristic (Year) & $\begin{array}{l}\text { All Counties } \\
\text { Combined }\end{array}$ & $P$ Value & \multicolumn{5}{|c|}{ Stratified by 2013 Rural Urban Continuum Code (RUCC) } \\
\hline Population change (2010-2013), \% & 1 & .03 & 2 & 1 & 2 & 0 & 1 \\
\hline Aged $\geq 65$ (2013), \% & 19 & $<.001$ & $13^{b}$ & 19 & $14^{b}$ & $23^{c}$ & $23^{c}$ \\
\hline Non-Hispanic white (2013), \% & 90 & $<.001$ & $92^{b}$ & $66^{c}$ & $90^{\mathrm{b}}$ & $88^{b}$ & $94^{b}$ \\
\hline $\begin{array}{l}\text { High school graduates aged } \geq 25 \text { y } \\
(2008-2012), \%\end{array}$ & 84 & .003 & $94^{b}$ & 90 & $84^{c}$ & 89 & 90 \\
\hline $\begin{array}{l}\text { No. of persons per household } \\
\text { (2008-2012), mean (SD) }\end{array}$ & $2.4(0.3)$ & .006 & $2.3(0)$ & $2.3(0)^{b}$ & $2.9(0.3)^{c}$ & $2.4(0.2)$ & $2.4(0.3)$ \\
\hline $\begin{array}{l}\text { Population living below poverty level } \\
(2008-2012), \%\end{array}$ & 20 & $<.001$ & 17 & $23^{b}$ & $25^{b}$ & 19 & $12^{\mathrm{c}}$ \\
\hline
\end{tabular}

Abbreviation: SD, standard deviation.

a RUCCs range from 1 through 10: ranges 1 through 3 are classified as metro (urban; counties in metro areas; population $\geq 250,000$ ), and 4 through 10 as nonmetro (rural; counties not in metro areas; population <250,000).

b, $c$ Values within a row that do not share a common superscripted letter $(b, c)$ are significantly different $(P<.01)$, whereas values that do share a common superscripted letter are not significantly different. 
Table 2. Analysis of Variance of NEMS-S Scores for Fruits and Vegetables by County Rurality Measured by 2013 Rural Urban Continuum Code $(n=20)$, Study on Availability, Price, and Quality of Fruits and Vegetables, Montana, 2014

\begin{tabular}{|l|r|r|r|r|}
\hline \multirow{2}{*}{ RUCC $^{a}$} & \multicolumn{4}{|c|}{ NEMS-S Score, Mean (SD) } \\
\cline { 2 - 5 } & \multicolumn{2}{|c|}{ Total $^{\text {b }}$} & Availabilityc & \multicolumn{1}{c|}{ Price $^{\text {d }}$} \\
\hline 3 & $28.7(7.4)$ & $22.7(2.5)$ & $3.7(4.7)$ & Quality \\
\hline 6 & $28.2(5.5)$ & $18.5(5.2)$ & $3.7(2.5)$ & $5.7(0.6)$ \\
\hline 8 & $14.7(17.5)$ & $9.0(11.5)$ & $2.0(3.5)$ & $3.7(3.2)$ \\
\hline 9 & $25.5(4.7)$ & $19.5(2.6)$ & $2.5(1.3)$ & $3.5(2.6)$ \\
\hline
\end{tabular}

Abbreviation: NEMS-S, Nutrition Environment Measures Survey for Stores; RUCC, rural-urban continuum code; SD, standard deviation.

a RUCCs range from 1 through 10: ranges 1 through 3 are classified as metro (urban; counties in metro areas; population $\geq 250,000$ ), and 4 through 10 as nonmetro (rural; counties not in metro areas; population <250,000).

$\mathrm{b}$ Of 54 possible points; $P=.35$, Kruskal-Wallis test for overall differences in NEMS-S scores by RUCC.

${ }^{c}$ Of 30 possible points; $P=.17$, Kruskal-Wallis test for overall differences in NEMS-S scores by RUCC.

$\mathrm{d}$ Of 18 possible points; $P=.87$, Kruskal-Wallis test for overall differences in NEMS-S scores by RUCC.

e 6 possible points; $P=.03$, Kruskal-Wallis test for overall differences in NEMS-S scores by RUCC. 